\title{
Sustainable Management of a Matured Oil Palm Plantation in UPM Campus, Malaysia Using Airborne Remote Sensing
}

\author{
Kamaruzaman Jusoff \\ Faculty of Forestry, Universiti Putra Malaysia \\ 43400, Serdang, Selangor, Malaysia \\ Tel: 60-894-7176_E-mail: kamaruz@putra.upm.edu.my
}

This project is funded by Universiti Putra Malaysia and Aeroscan Precision (M) Sdn Bhd (Sponsoring information)

\begin{abstract}
Accurate and reliable near-real time information is needed for a sustainable oil palm plantation management, especially on plant quality and health. Airborne remote sensing provides the effective recent agricultural crop information for the oil palm plantation industry planning, management and sustainable development. A study on the characteristic of a matured oil palm plantation in UPM campus was conducted using airborne hyperspectral remote sensing technique. Airborne hyperspectral remote sensing can be used as an effective tool in monitoring the characteristic of oil palm plantation in order to predict and manage the oil palm production. The general objective of this study is to assess the capability and usefulness of UPM-APSB's AISA airborne hyperspectral sensor to determine the characteristic of a matured oil palm plantation for its sustainable development while the specific objective is to identify, classify and produce the thematic map of matured oil palm plantation in the study site. The age of the oil palm plantation used in this study is 27 years old. Sobel filtering was used to enhance the image. Spectral Angle Mapper (SAM) analysis was then used to classify the characteristic of the plantation within the study area. A thematic map of 27 years old matured oil palm plantation was produced and the characteristic of the oil palm plantation in the study site was identified as 173 healthy, 7 dead, 9 stressed oil palm trees and open areas in the plantation with a mapping accuracy of $93.33 \%$. This has shown that UPM-APSB's AISA airborne hyperspectral sensor is capable of mapping a matured oil palm plantation with such characteristics for its sustainable management and future development.
\end{abstract}

Keywords: Oil palm, Precision, Sustainable production, Individual tree, Plantation characteristics

\section{Introduction}

In Asia, the main oil palm producing countries are Malaysia; the Malaysian oil palm industry recorded an impressive performance in 2006. The total oil palm planted areas in 2006 were 4.17 million ha. While, the total exports of oil palm products were 20.13 million tonnes in 2006. This scenario trigger the export earnings of oil palm products rose to a record RM 31.8 billion in 2006. The industry also saw exciting developments shaping up in the local bio-fuel industry with the Honourable Prime Minister of Malaysia launching the "Envo Diesel" (palm olein blend with diesel) (http://www.econ.mpob.gov.my/economy/EID Review06.htm). Due to the importance of oil palm to the country, accurate and reliable information is needed for oil palm plantation management, especially on plant quality, phenology, health and yield prediction. However, in the context of Malaysia, lack of data, cost effective and timely processing of information for oil palm management planning are major constraints, which hold up decision-making. Currently data collection for oil palm planning and management depend mainly on traditional methods of sample surveys in the field. The main task of Malaysian agriculture agencies is to improve the reliability, timeliness and cost effectiveness of data collection techniques. Remote sensing was identified as effective recent agricultural crop information for the global oil palm plantation industry planning (http://www.gisdevelopment.net/aars/acrs/2000/ps3/ps302.asp).

Monitoring characteristics of oil palm plantation is beneficial and important for oil palm planters as reported by McMorrow (1995), Lukman \& Poeloengan (1996) and Ibrahim et al. (2000). The use of airborne hyperspectral imaging system to accomplish this task is making the job easier and fast. Airborne hyperspectral imaging is only one of many remote sensing tools available to oil palm managers, but it offers the most comprehensive perspective of all. Airborne hyperspectral imaging system can provide accurate vegetation map quickly and cost effectively. The data are capable of providing repetitive and continuous information on different scales. Apart from this, airborne hyperspectral imaging 
system could provide cost competitive, quick information and "real time" data on oil palm plantation than satellite remote sensed data. Currently, data collection for oil palm planning and management depend mainly on traditional methods of sample surveys in the field. Identifying the characteristics of oil palm plantation using this traditional method is acquire a relatively time consuming and high expenditure. While satellite based sensing technique are limited, unsuitable and ineffective because of lower resolution, resulting inaccurate and non-detail data about their characteristics in the plantation. Supervising physical condition of oil palm plantation using real time information is essential for monitoring disease or pest outbreaks in order to predict and manage oil palm production. Airborne hyperspectral imaging system can provide real time and high spatial resolution data for identifying characteristic of oil palm plantation. Airborne hyperspectral imaging system has significant potential to aid oil palm monitoring and detection efforts. It also provides a cost-effective method to map oil palm and at the same time provides site-specific assessments of management practices and growth performance of the palms.

The general objective of this study is to assess the capability and usefulness of UPM-APSB's Airborne Imaging Spectrometer for Application (AISA) sensor to determine the characteristic of a matured oil palm plantation. The specific objective is to identify, classify and produce the thematic map of such plantation for its future sustainable palm oil production by an individual tree basis.

\section{Methodology}

\subsection{Description of study area}

The study area is located in main campus of Universiti Putra Malaysia (UPM), Serdang, Selangor, Malaysia. It is located approximately $23 \mathrm{~km}$ from the south of Kuala Lumpur and $16 \mathrm{~km}$ north of Putrajaya (Latitude $\mathrm{N} 1^{\circ} 24^{\prime}$ to $\mathrm{N} 2^{\circ}$ $32^{\prime}$ and Longitude E $102^{\circ} 42^{\prime}$ to E $103^{\circ} 38^{\prime}$ ). UPM campus area covers about 1,214 ha and 121 ha are used for administration buildings, faculties, lecture hall, student's dormitories, staff housing and recreation field. The rest of the area is currently cultivated with many crops that include oil palm, rubber tree, orchards and pasture. A significant portion of the farm is utilized as share-farm by the students for their practical and research work and also by the academic staffs for their research programs. The oil palm plantation used in this study is located at latitude $\mathrm{N} 2^{\circ} 59^{\prime}$ $15.73^{\prime \prime}-\mathrm{N} 2^{\circ} 59^{\prime} 11.70^{\prime \prime}$ and longitude E $101^{\circ} 43^{\prime} 21.51^{\prime \prime}-\mathrm{E} 101^{\circ} 43^{\prime} 25.66^{\prime \prime}$. The age of the oil palm plantation in the study site is 27 years old.

\subsection{Equipments and software}

UPM-APSB's AISA airborne hyperspectral sensor is designed to collect accurate and reliable information of the earth surface. UPM-APSB's AISA hyperspectral systems is a complete, pushbroom imaging systems, consisting of a hyperspectral sensor head, a miniature GPS/INS sensor, and a data acquisition unit in a rugged PC. The system is designed to be user and field friendly. It is quick to install and remove from any aircraft even the lightest ones, and they provide timely, accurate and reliable information. The system includes an in-flight configuration setting, which allows alterations to be made easily for each exercise. UPM-APSB's AISA sensor is also the best mix of economy and performance depending on the application requirements. The total system weight is less than $15 \mathrm{~kg}$ (ca.35 lbs) from which the front-end weighs only $4 \mathrm{~kg}(9 \mathrm{lbs})$. Global Positioning System (GPS) was used to determine the position of the oil palm tree in oil palm plantation. It was used during the ground truth to compare the data taken by the UPM-APSB's AISA sensor with the ground data. The Environment for Visualizing Images (ENVI) software was used to process the raw hyperspectral data including the radiometric correction, band combination, image enhancement and other basic image processing system for data analyzing. This is because ENVI software package is an easy-to-use remote sensing image analysis and GIS data integration and offers a robust suite of spectral identification and exploitation tools in the industry.

\subsection{Methodology}

Image data was obtained by UPM-APSB's AISA airborne hyperspectral sensor, an airborne imaging spectrometer. The sensor was flown at an altitude of $1000 \mathrm{~m}$ from the ground at a spatial resolution of $1 \mathrm{~m}$. The aircraft flying speed was 120 knots $\left(60 \mathrm{~ms}^{-1}\right)$. These images were used for mapping of matured oil palm plantation of the study site. The entire digital image capturing process was taken by the Aeroscan Precision (M) Sendirian Berhad (APSB) which is located at the Forest Geospatial Information and Survey Lab, Lebuh Silikon, UPM. Figure 1 shows the raw image of matured oil palm plantation of the study site with band R19 G11 B2.

\section{$<<$ Fig. 1. Raw image of matured oil palm plantation of the study site (Band - R19 G11 B2)>>}

Prior to data analysis, initial pre-processing on the raw data was usually carried out to correct for any distortion due to the characteristics of the imaging system and imaging conditions. These procedures include radiometric correction to correct for uneven sensor response over the whole image and geometric correction to correct for geometric distortion due to Earth's rotation and other imaging conditions (such as oblique viewing). The image was also transformed to conform to a specific map projection system. Image Enhancement operations are carried out to improve the interpretability of the image by increasing apparent contrast among various features in the scene. There is no ideal or 
best image enhancement because the result are ultimately evaluated by humans, who make subjective judgements as to whether a given image enhancement is useful (Jensen, 1996). The enhancement techniques depend upon two factors mainly, the digital data (i.e. with spectral bands and resolution) and the objectives of interpretation. As an image enhancement technique often drastically alters the original numeric data, it is normally used only for visual (manual) interpretation and not for further numeric analysis. Contrast enhancement was performed to change the range of values in the image to increase its contrast. This process expands the original input brightness values to make use of the total range of the output device and thus increase the quality of te processed image. Different sets of band combinations was displayed to create a different composite effects and increased information on oil palm plantation cover and its characteristics. Image Classification based on their reflectance was also performed using the supervised classification Spectral Angle Mapper (SAM) algorithm. Redundant bands were removed before classification took place.

Ground verification was performed to verify and match the characteristics of features in the image that have been retrieved from the airborne hyperspectral images. Ground verification was carried out by taking the exact location of the physical condition in the oil palm plantation to assess the accuracy between the UPM-APSB's AISA DGPS and also the ground GPS. Photographs were taken and parameters related to physical condition of oil palm plantation to this study were recorded. The data was also collected in the form of latitude and longitude of the position of the features present in the oil palm plantation using GPS. A total of 15 sample points were chosen randomly and visited during ground verification work. These 150 sample points were used to verify the accuracy percentage of the study. All the data recorded were then matched with the data taken by the airborne on-board DGPS. All collected data obtained from the ground verification were used to determine the accuracy of mapping in this study. Ground verification points based on the GPS readings were prepared earlier according to the processed image. Data obtain from ground verification were closely related to the accuracy assessment. This process is needed to ensure that the classification has been done was precise as to the real condition on the ground. In this study, accuracy assessment was carried out by using 150 sample points which were chosen randomly from the image. The sample points were checked on the ground to make sure they matched with the parameters recorded in the image to calculate the mapping accuracy percentage in this study.

\section{Results and discussion}

Selecting appropriate bands to be used to create a useful and attractive image is very essential for making enhanced colour composite image which is suitable for interpreting land cover pattern. In this study, band 10, 16, 8 (RGB) with sharpening enhancement were selected to be the best combination and to get the sharpest image for further processing. It was used for further analysis in image classification since it provides a well enhanced colour composite image with respect to the oil palm cover. Bright red areas on the image (Figure 1) represent high near-infrared reflectance, usually corresponding to healthy vegetation. In this study, Sobel filter was found to be the most suitable filter to be applied to the airborne hyperspectral imagery especially for visual interpretation of vegetation on the image. The Sobel filter is a non-linear edge enhancement, special case filter that uses an approximation of the true Sobel function, and is a preset 3 x 3, non-linear edge enhancement operator. The size of the filter cannot be changed and no kernel editing is possible. Figure 2 showed the enhanced image with Sobel Filter that came out to be the best filter for this study.

\section{$<<$ Fig.1. Raw image of matured oil palm plantation of the study site (Band - R19 G11 B2) >> \\ $<<$ Fig.2. Image after enhancement (Sobel 75\%) \\ R10G16B8 (band combination) >>}

Figure 3 showed the spectral signatures derived from the UPM-APSB's AISA airborne data for the oil palm trees that are available in this study site. It can be clearly seen that oil palm tree has its own unique spectral reflectance that made it possible to be differentiated from others. The area of oil palm plantation can be easily distinguished from other land areas with its green colour reflectance occurring in the middle of the whole image.

\section{$<<$ Fig.3 Spectral signatures of a matured oil palm plantation in UPM Campus $>>$}

The image clearly differentiated the individual oil palm trees from the other features such as healthy oil palm tree (green), stressed oil palm tree (red), dead oil palm tree (blue) and open area or canopy gaps (white) after SAM was applied to the image. The algorithm determines the spectral similarity between two spectra by calculating the angle between the spectra, treating them as vector in a space with dimensionality equal to the number of bands.

Spectral reflectance of the matured oil palm plantation in the sample plot area was selected randomly from the image to check the curve of spectral reflectance. This step was done to confirm that the classes that have been map out belonged to the respective classes. Figures $4 \mathrm{a}-4 \mathrm{c}$ showed that the various spectral reflectances of the sampled healthy, dead, vs. stressed oil palm trees and open area in the plantation,

\section{<<Figs. 4a-4c. Spectral signatures of stressed, healthy and dead oil palm individual trees $>>$}

Based on the image and the spectral reflectance signatures in Figures 4a-4c, it can be seen that every single class of the matured oil palm plantation have their own unique spectral signature. These subtle differences were used to classify the 
physical characteristic of the oil palm plantation. The open area class showed a different reflectance signature pattern within a range of $450-700 \mathrm{~nm}$ due to the different intensity of the grass cover over some parts of the open areas. The healthy oil palm trees have higher reflectance between the frequency ranges of 700-900 nm. This is due to the higher chlorophyll concentration in the fronds of healthy trees. Higher chlorophyll concentration will produce shiny cuticle on leaves surface, which led to the increasing reflectance on leaves. Hence, our eyes observe healthy vegetation as green in color because of the very high absorption of blue and red energy by plant leaves and the high reflection of green energy. A similar study by Ourcival (1999) and McMorrow (1995) reported that the palm's development factor such as leaf age and plant species may cause dissimilar reflectance spectra.

Meanwhile, the "stressed" or diseased infected trees seem to have a lower level of chlorophyll and mineral deficiency compared to the healthier palms. Iron, magnesium, nitrogen and sunlight are necessary for chlorophyll production. Lacking in any one of these can lead to yellowing of the oil palm fronds which may lead to the decrease in the spectral reflectance of the leaves within a range of $450-500 \mathrm{~nm}$. Dead oil palm trees have the lowest spectral reflectance probably due to its lowest moisture content that least absorbs the reflectance energy in the infrared portion of the electromagnetic spectrum and at the same time decreases its reflectance. The stressed tree recorded during ground verification was probably caused by the lightning strikes. Oil palm trees have less resistance to lightning because of the sap and water inside it are better conductors than air. Some of the oil palm trees may suffer a light damage from a lightning strike while others may go completely harmed depending on the intensity of the lightning.

Results of the ground verification data showed that 140 parameters of oil palm plantation confirm available on the ground compared to 150 parameters in the image. The mapping accuracy for this study is $93.33 \%$ as calculated below:

$$
140 / 150 * 100 \%=93.33 \%
$$

However, the misclassified parameter was the dead oil palm trees which had been misclassified as the open area due to their short residual stump.

The availability of $1 \mathrm{~m}$ spatial resolution airborne hyperspectral imaging system provides better alternatives for individual oil palm tree counting. Counting trees in an image is much more manageable as workers can label the trees easily on the image. From the sample image in Figure 5, 173 healthy oil palm trees, 9 stressed oil palm trees and 7 dead oil palm trees were detected for the whole study area. Finally, the output thematic map of matured oil palm plantation) was produced as shown in Figure 6. The green colour represents the healthy oil palm trees, red represent the stressed oil palm trees, blue colour represent the dead oil palm trees while black represent unclassified areas. This geospatial map is useful in planning and managing the oil palm plantation. With an airborne hyperspectral data, identifying the characteristics of oil palm plantation will be cost-effective and time-efficient.

\section{$<<$ Fig.6. Thematic Map of Matured Oil Palm Plantation>>}

\section{Conclusions}

A thematic map of a matured oil palm plantation was developed from airborne hyperspectral imaging system to further plan for its sustainable management and palm oil production. It can be used to identify the characteristics of the oil palm plantation. This information will definitely aid the management of the oil palm industry in UPM Campus and elsewhere The UPM-APSB's AISA airborne sensor is capable and useful for determining the characteristic of matured oil palm plantation such as healthy oil palm tree, dead oil palm tree, stressed oil palm tree and open area in the plantation with mapping accuracy of $93.33 \%$. The characteristics of the plantation under study indicated that there are 173 healthy, nine "stressed" and seven dead oil palm trees. Future research should be focused on identifying pest and disease infested individual oil palm trees using airborne hyperspectral imaging system.

\section{References}

http://www.econ.mpob.gov.my/economy/eid_review06.htm (2006). Overview of The Malaysian Oil Palm Industry 2006.

http://www.econ.mpob.gov.my/economy/EID_Review06.htm.

http://www.gisdevelopment.net/aars/acrs/2000/ps3/ps302.asp

Ibrahim, S., Zainal Abidin Hasan and Mariamni Khalid. (2000). Application of Optical Remote Sensing Technology for Oil Palm Management. Proceedings of The $21^{\text {st }}$ Asian Conference on Remote Sensing. 4-8 December 2000, Taipei, Taiwan. 3 p.

Jensen, J.R. (1996). Introductory Digital Image Processing: A Remote Sensing Perspective, 2nd Edition. NJ: Prentice-Hall.

Lukman, F.M., and Z. Poeloengan. (1996). Application of Remote Sensing Technique for Oil Palm Plantation Management. Proceedings of the 1997 PORIM International Palm Oil Congress "Competitiveness for the 21st Century". p. $460-467$. 
McMorrow, J.M. (1995). Relation of Oil Palm Spectral Response to Stand Age. Int. J. Remote Sensing, 16: $3203-3209$. Ourcival, J. M., R. Joffre and S. Rambal. (1999). Exploring the Relationship Between Reflectance and Anatomical and Biochemical Properties in Quercas ilex leaves. New Phytol. 143:351-364pp.

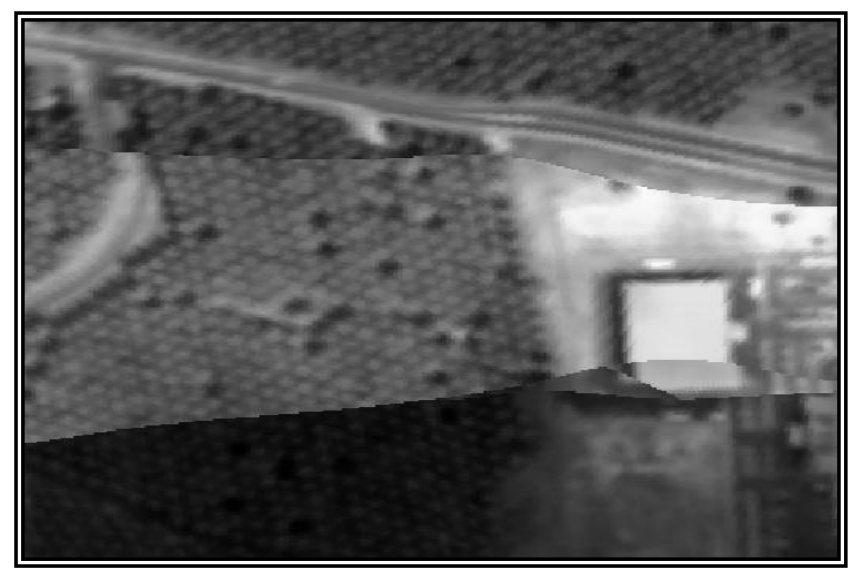

Figure 1. Raw image of matured oil palm plantation of the study site (Band - R19 G11 B2)

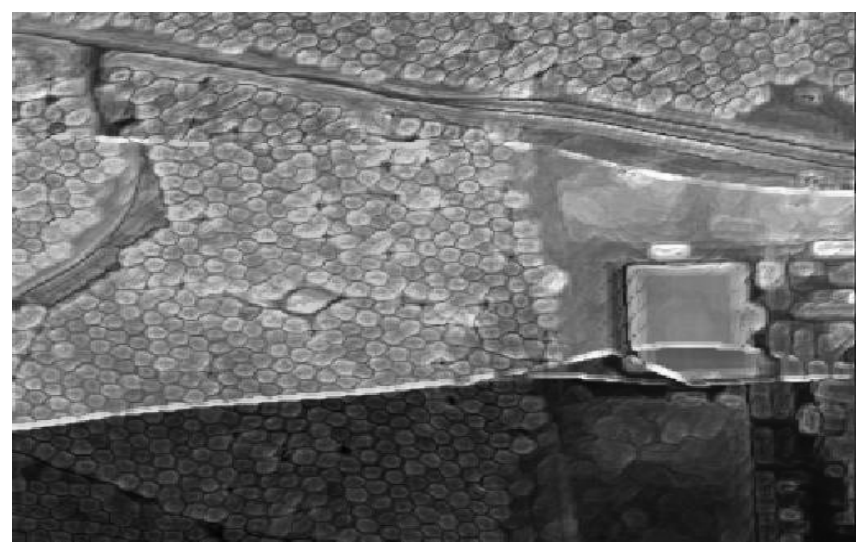

Figure 2. Image after enhancement (Sobel 75\%) R10G16B8 (band combination)

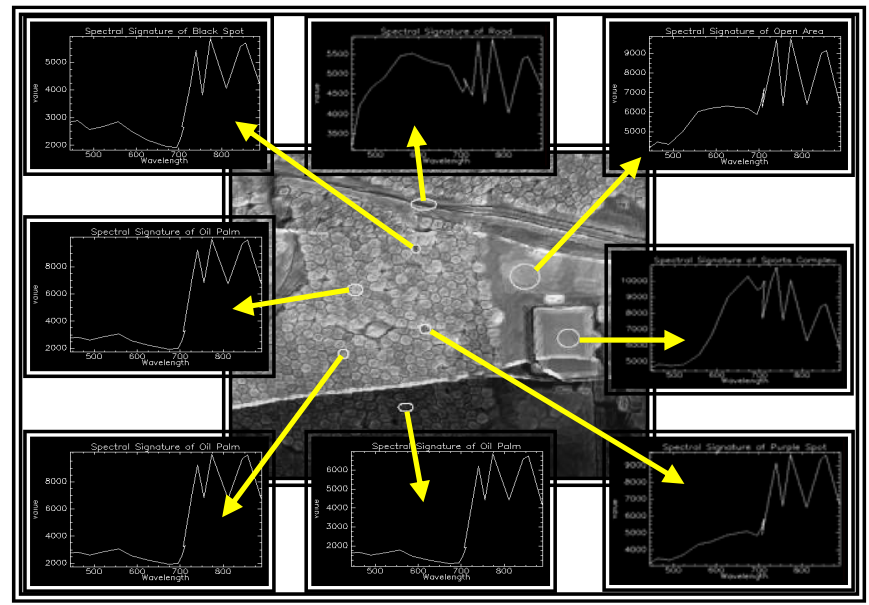

Figure 3. Spectral signatures of a matured oil palm plantation in UPM Campus 

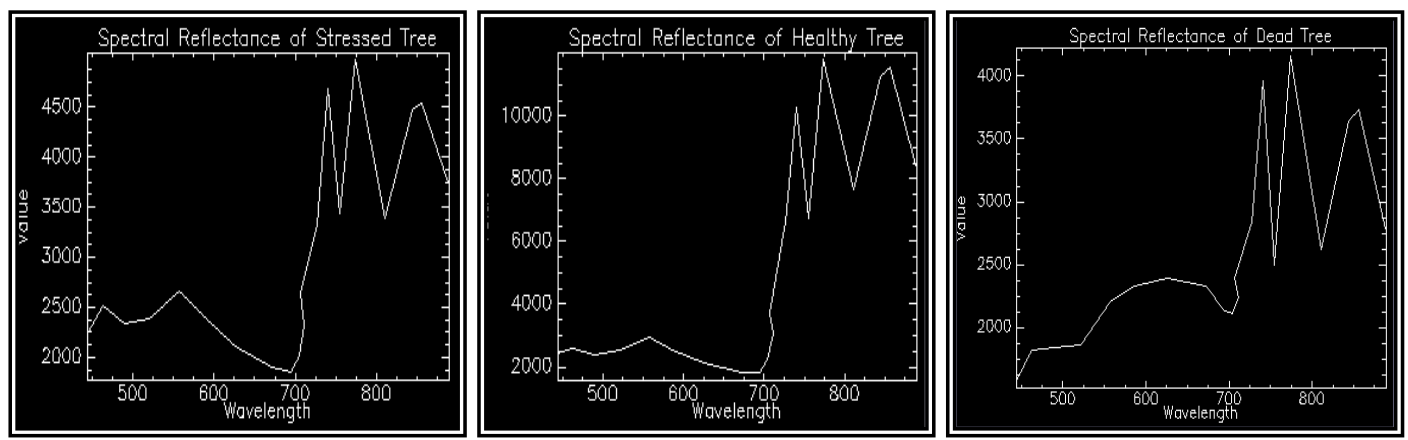

Figure 4a-4c. Spectral signatures of stressed, healthy and dead oil palm individual trees

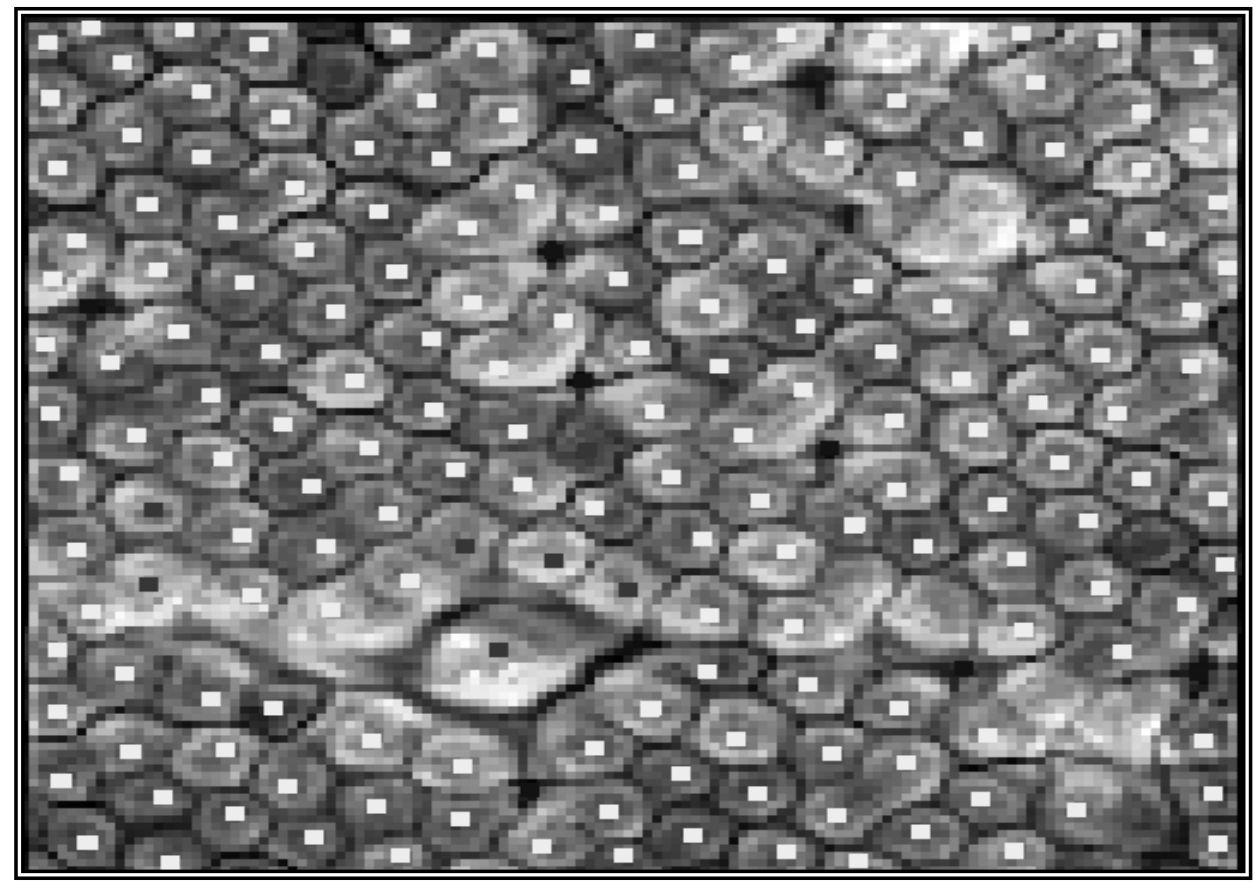

Figure 5. The airborne image showing an individual oil palm tree counting capability

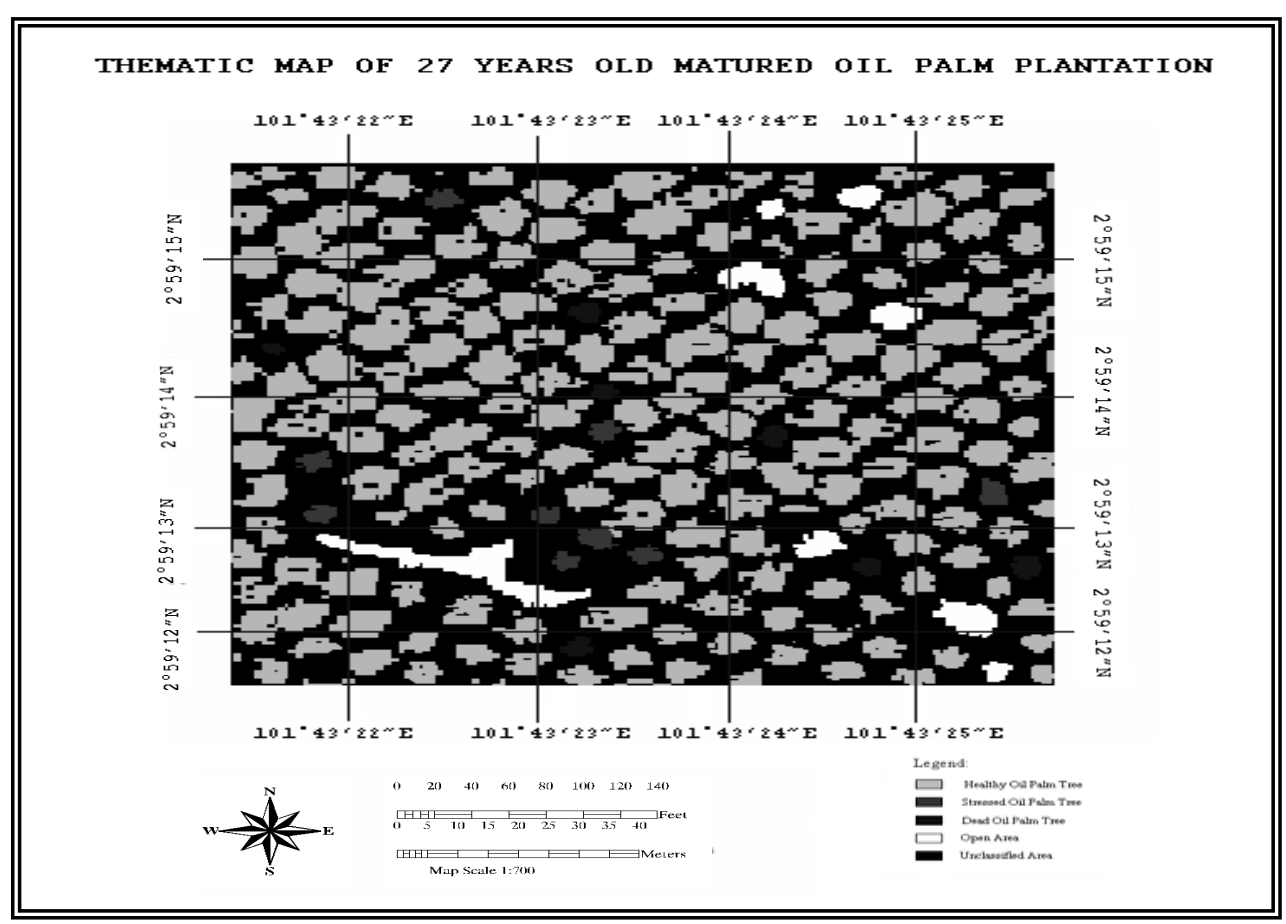

Figure 6. Thematic map of matured oil palm plantation 